\title{
Prediction of the Lifetime Integrity of a Nuclear Waste Container Material Based on Thermal Stability Studies
}

\author{
T.S. Edgecumbe Summers \\ T. Shen \\ R.B. Rebak
}

This paper was prepared for submittal to the
International Conference on Ageing Studies and Lifetime Extension of Materials
Oxford, United Kingdom

July 12-14, 1999

July 8, 1999

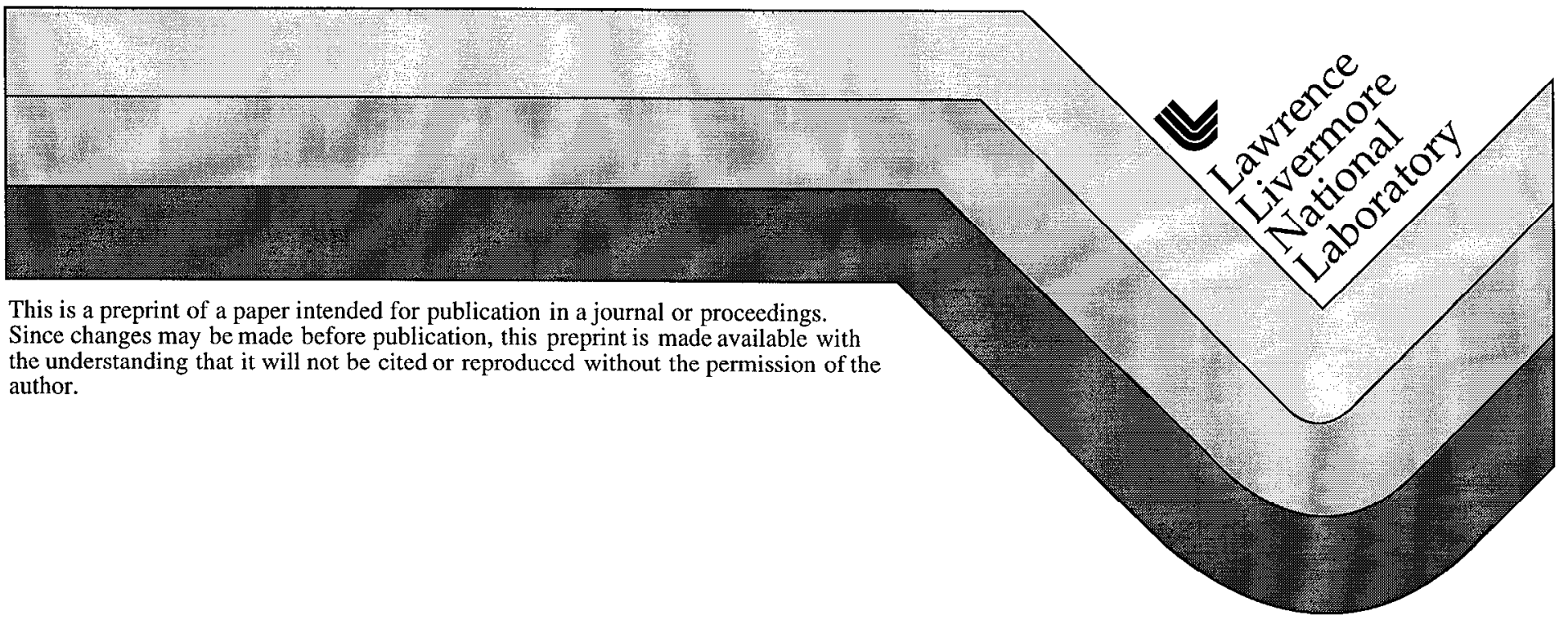




\section{DISCLAIMER}

This document was prepared as an account of work sponsored by an agency of the United States Government. Neither the United States Government nor the University of California nor any of their employees, makes any warranty, express or implied, or assumes any legal liability or responsibility for the accuracy, completeness, or usefulness of any information, apparatus, product, or process disclosed, or represents that its use would not infringe privately owned rights. Reference herein to any specific commercial product, process, or service by trade name, trademark, manufacturer, or otherwise, does not necessarily constitute or imply its endorsement, recommendation, or favoring by the United States Government or the University of California. The views and opinions of authors expressed herein do not necessarily state or reflect those of the United States Government or the University of California, and shall not be used for advertising or product endorsement purposes. 


\title{
Prediction of the Lifetime Integrity of a Nuclear Waste Container Material Based on Thermal Stability Studies
}

\author{
${ }^{1}$ Tammy S. Edgecumbe Summers, ${ }^{1}$ Tien Shen, and ${ }^{2}$ Raúl B. Rebak \\ ${ }^{\prime}$ Lawrence Livermore National Laboratory, 7000 East Ave, Livermore, CA; ${ }^{2}$ IIaynes \\ International, Inc., 1020 West Park Ave., Kokomo, IN.
}

The kinetics of precipitation in C-22 alloy (UNS N06022) was estimated through isothermal aging experiments at temperatures ranging from $427^{\circ} \mathrm{C}$ to $800^{\circ} \mathrm{C}$ for times up to $40,000 \mathrm{~h}$. The phases that formed, at least after the longer aging times, were identified by transmission electron microscopy (TEM). Aged samples were also examined using scanning electron microscopy (SEM) to determine when precipitation began on grain boundaries, completely covered grain boundaries, and began forming within the grains. This data was used to evaluate the kinetics of precipitation at lower temperatures using a simple exponential temperature dependence. The corrosion resistance of aged samples was investigated using the ASTM Specification G28B technique. The time to cause a significant increase in corrosion rate was also determined as a function of temperature and was fit to an exponential temperature dependence. Preliminary results indicate that $\mathrm{C}-22$ alloy base metal would remain a highly corrosion resistant, single-phase material for greater than 10,000 years at temperatures below approximately $300^{\circ} \mathrm{C}$.

\section{INTRODUCTION}

C-22 alloy, which is a Ni-base alloy with nominally $22 \%$ chromium (Cr), 13\% molybdenum (Mo), 3\% iron ( $\mathrm{Fe})$, and 3\% tungsten (W) all in weight percent, is currently being considered in the design of high-level radioactive waste disposal containers in the United States. Evaluation of this material is part of the Yucca Mountain Site Characterization Project. Due to radioactive decay of the waste, the temperature of the container could increase to temperatures as high as $350^{\circ} \mathrm{C}$, although 
current designs are aimed at keeping that temperature below approximately $300^{\circ} \mathrm{C}$. This temperature is low from a metallurgical point of view, but the container lifetime, defined as the time for which there is reasonable assurance of no leakage, must be greater than 10,000 years. Because of the extremely long times involved and because the phases that form in C-22 and other similar Ni-base alloys are known to have a detrimental effect on their mechanical (Matthews 1976, Tawancy 1980) and corrosion properties (Leonard 1969, Hodge 1973, Hodge and Kirchner 1976), phase stability of the heavily alloyed C-22 alloy is of concern.

In the fully annealed condition, C-22 alloy is a metastable facecentered cubic (FCC) solid solution that can precipitate one or more of several phases under certain conditions. At higher temperatures (above about $600^{\circ} \mathrm{C}$ ), several intermetallic phases have been observed to form in Ni-Cr-Mo alloys (Leonard 1969, Hodge 1973, Tawancy et al. 1983, Raghavan et al. 1982, Tawancy 1996 and 1980, and Summers et al. 1998). Two of the intermetallics that form, $\mu$ phase and $P$ phase, are similar both chemically and crystallographically (Leonard 1969, Raghavan et al. 1982, Cieslak et al. 1986). A small amount of $\sigma$ phase has been observed in C-22 alloy aged at $760^{\circ} \mathrm{C}$ (Summers et al. 1998) and in C-22 alloy welds (Cieslak et al. 1986). Also at the higher temperatures, carbides have been observed (Hodge 1973 and Tawancy et al. 1983) and are generally believed to be Mo-rich $\mathrm{M}_{6} \mathrm{C}$ or $\mathrm{M}_{12} \mathrm{C}$ type carbides. These phases tend to be rich in either $\mathrm{Mo}$ or $\mathrm{Cr}$, which are the elements that give $\mathrm{C}-22$ alloy its excellent corrosion resistance. Precipitation of these phases leads to local $\mathrm{Cr}$ and Mo depletion, which can cause an increased susceptibility to localized corrosion (Leonard 1969, Hodge 1973, Tawancy et al. 1983, Heubner et al. 1989, Tawancy 1996 and 1980).

At lower temperatures (below approximately $600^{\circ} \mathrm{C}$ ), long-range ordering has been observed to occur in Ni-Cr-Mo alloys (Tawancy et al 1983, Tawancy 1996 and 1980, Rebak and Koon 1998, and Summers et al. 1998). The ordered phase that forms in $\mathrm{C}-22$ alloy is $\mathrm{Ni}_{2}(\mathrm{Cr}, \mathrm{Mo})$, which has the $\mathrm{Pt}_{2} \mathrm{Mo}$ structure. This phase has been linked to an increased susceptibility of Ni-Cr-Mo alloys to hydrogen embrittlement and stress corrosion cracking (Tawancy et al. 1983).

To determine whether the solid solution will be stable for 10,000 years requires that the kinetics of precipitation be studied. Further, 
phases forming at high temperatures where the rate of formation is not prohibitively long must be studied and the results extrapolated to the lower temperatures expected in the potential repository. Although the phases forming and their effect on the properties have been studied extensively, very little work has been done on the kinetics of precipitation. Hodge (1973) measured volume fraction of precipitation in C-276, a Ni-Cr-Mo alloy similar to C-22 alloy with nominally $16 \%$ $\mathrm{Cr}, 16 \% \mathrm{Mo}, 4 \% \mathrm{~W}, 5 \% \mathrm{Fe}$, and found the activation energy to be 260 $\mathrm{kJ} / \mathrm{mol}(62 \mathrm{kcal} / \mathrm{mol})$. Heubner et al. (1989) looked at aged C-22 alloy samples optically and produced a Time-Temperature-Transformation (TTT) diagram, but it was not within the scope of that paper to extrapolate the kinetics of precipitation to lower temperatures. The preliminary results presented here are a first attempt at measuring the kinetics of intermetallic precipitation in $\mathrm{C}-22$ alloy.

\section{EXPERIMENTS}

Samples of C-22 alloy in the form of $1 / 2$ " thick plate were aged for times up to 40,000 hours at $427,482,538,593,649,704,760$, and $800^{\circ} \mathrm{C}$. More than one heat was used in this study, and the compositions are given in Table 2.1. Most of the aged samples came from heat 2277 6-3181. The samples aged for $16,000 \mathrm{~h}$ came from heat 2277-0-3195, and those aged at $427^{\circ} \mathrm{C}$ came from heat $2277-7-3173$. These were the samples examined in TEM. Of the remaining samples, only the sample aged for $2000 \mathrm{~h}$ at $760^{\circ} \mathrm{C}$ came from heat $2277-7-3145$. The aging was done in air, and the temperature was maintained to within $\pm 6^{\circ} \mathrm{C}$.

Table 2.1. Mill compositional analyses (wt.\%) of the heats used in this study.

\begin{tabular}{|c|c|c|c|c|c|c|c|}
\hline Heat & $\mathbf{A l}$ & $\mathbf{C}$ & $\mathbf{C o}$ & $\mathbf{C r}$ & $\mathbf{F e}$ & $\mathbf{M g}$ & $\mathbf{M n}$ \\
\hline $2277-6-3181$ & 0.32 & .0040 & $\mathbf{1 . 1 1}$ & 21.59 & 3.90 & .023 & 0.28 \\
\hline $2277-7-3145$ & 0.28 & .0039 & .87 & 21.81 & 4.23 & .036 & 0.27 \\
\hline $2277-7-3173$ & 0.26 & .0031 & 1.13 & 21.64 & 3.77 & .020 & 0.24 \\
\hline $2277-0-3195$ & 0.29 & .003 & 1.74 & 21.10 & 4.7 & .010 & 0.21 \\
\hline Heat & $\mathbf{M o}$ & $\mathbf{N}$ & $\mathbf{N b}$ & $\mathbf{N i}$ & $\mathbf{S i}$ & $\mathbf{V}$ & $\mathbf{W}$ \\
\hline $2277-6-3181$ & 13.64 & 0.03 & $<0.05$ & 55.93 & .024 & 0.17 & 3.03 \\
\hline $2277-7-3145$ & 13.36 & 0.04 & $<0.05$ & 56.27 & .028 & 0.15 & 2.80 \\
\hline $2277-7-3173$ & 13.46 & 0.04 & $<0.05$ & 55.78 & .027 & 0.14 & 3.01 \\
\hline $2277-0-3195$ & 13.50 & 0.02 & $<0.05$ & 55.67 & .023 & 0.12 & 2.90 \\
\hline
\end{tabular}


Metallographically prepared samples were examined in a SEM to determine the amount of precipitation that had occurred. These samples were prepared using standard polishing techniques and an clectrochemical etch at 6 Volts for a few seconds in a solution of $5 \mathrm{~g}$ oxalic acid in $95 \mathrm{ml}$ of $37 \% \mathrm{HCl}$. Samples for TEM were mechanically thinned to $175-200$ $\mu \mathrm{m}$ followed by jet polishing in a $5 \%$ perchloric-acetic acid solution at room temperature and 40-60 V. Additional samples without preferential etching of second phases were prepared by dimpling and ion milling. The foils were examined in a JEOL JEM-200CX TEM operated at $200 \mathrm{kV}$. Only samples that were aged for $16,000 \mathrm{~h}$ and one sample aged for $40,000 \mathrm{~h}$ at $427^{\circ} \mathrm{C}$ were examined in TEM.

The susceptibility of mill-annealed and aged C-22 samples to intergranular corrosion was tested using the American Society for Testing and Materials (ASTM) Specification G28 standard procedure, method B (ASTM 1997). Method B is an immersion test in a boiling solution consisting of $23 \%$ sulfuric acid, $1.2 \%$ hydrochloric acid, $1 \%$ ferric chloride, and $1 \%$ cupric chloride. This method is particularly useful in determining when there is significant grain boundary precipitation since it shows a stepwise increase in corrosion rate when such precipitation exists. Samples were ground on 120-grit abrasive paper before measuring the specimen dimensions. They were then cleaned, rinsed in acetone and dried before weighing to the nearest $0.001 \mathrm{~g}$. The samples were immersed in the above solutions for 24 hours.

\section{RESULTS}

\subsection{Phases Forming in C-22 Alloy}

The samples aged for 16,000 hours at $593,649,704$, and $760^{\circ} \mathrm{C}$ were discussed in a previous publication (Summers et al. 1998). These samples have been studied further, and the results are presented here as an indication of the phases that form during aging at the various temperatures involved in this study. The other samples used for the kinetic arguments below were not examined in TEM. Several phases were observed to form in $\mathrm{C}-22$ alloy: $\mathrm{P}, \mu, \sigma$, carbide, and $\mathrm{Ni}_{2}(\mathrm{Cr}, \mathrm{Mo})$ 
long-range ordering (LRO). LRO was observed in the sample aged at $593^{\circ} \mathrm{C}$ for $16,000 \mathrm{~h}$ and in the sample aged at $427^{\circ} \mathrm{C}$ for $40,000 \mathrm{~h}$. This is consistent with an ordering temperature near $600^{\circ} \mathrm{C}$ (Tawancy et al. 1983).
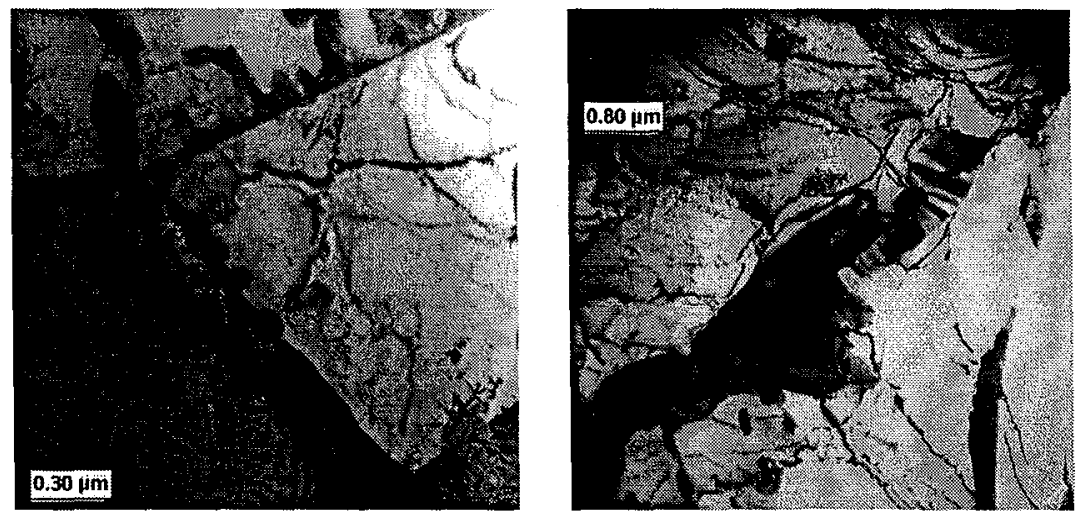

Figure 3-1. TEM micrographs of samples aged $649^{\circ} \mathrm{C}$ (left) and $704^{\circ} \mathrm{C}$ (right). The precipitates at left are $\mathrm{P}$ and $\mu$ phase. The precipitates at right are carbide and $\mu$ phase.

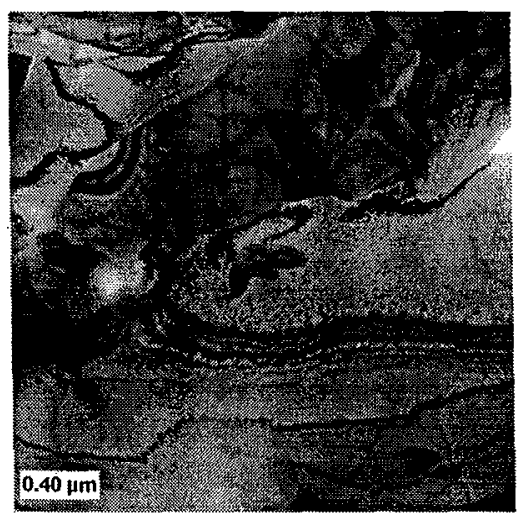

Figure 3-2. TEM micrograph showing grain boundary phases in C-22 aged for $16,000 \mathrm{~h}$ at $704^{\circ} \mathrm{C}$. The larger phase was indexed as $\sigma$ phase, and the smaller faulted phase is $\mu$ phase. 
$\mathrm{P}$ phase was observed in all four samples while $\mu$ phase formed in all samples except the one aged at $593^{\circ} \mathrm{C}$. At $593^{\circ} \mathrm{C}, \mathrm{P}$ phase was observed only at the grain boundaries. As the aging temperature increased, more $\mu$ and $\mathrm{P}$ phase precipitation occurred within the grains. Grain boundary carbide precipitation was observed in the samples aged at 593 and $704^{\circ} \mathrm{C}$. Due to the small amount of carbide present in these samples and to the small volume examined in TEM, it is likcly that carbides also form at $649^{\circ} \mathrm{C}$. It is not certain whether they also form at $760^{\circ} \mathrm{C}$. Due to the similarity between the $\mathrm{M}_{6} \mathrm{C}$, the $\mathrm{M}_{12} \mathrm{C}$, and the $\mathrm{M}_{23} \mathrm{C}_{6}$ carbide crystal structures, the specific carbide forming in these samples was not identified. Figure 3-1 gives examples of $\mu$ and $P$ phase in the sample aged at $649^{\circ} \mathrm{C}$ and carbide and $\mu$ phase in the sample aged at $704^{\circ} \mathrm{C}$. Sigma phase was observed in the samples aged at 704 and $760^{\circ} \mathrm{C}$ (see Figure 32). The amount of $\sigma$ in these samples was small compared to the amount of $\mu$ and $P$, only a few percent.
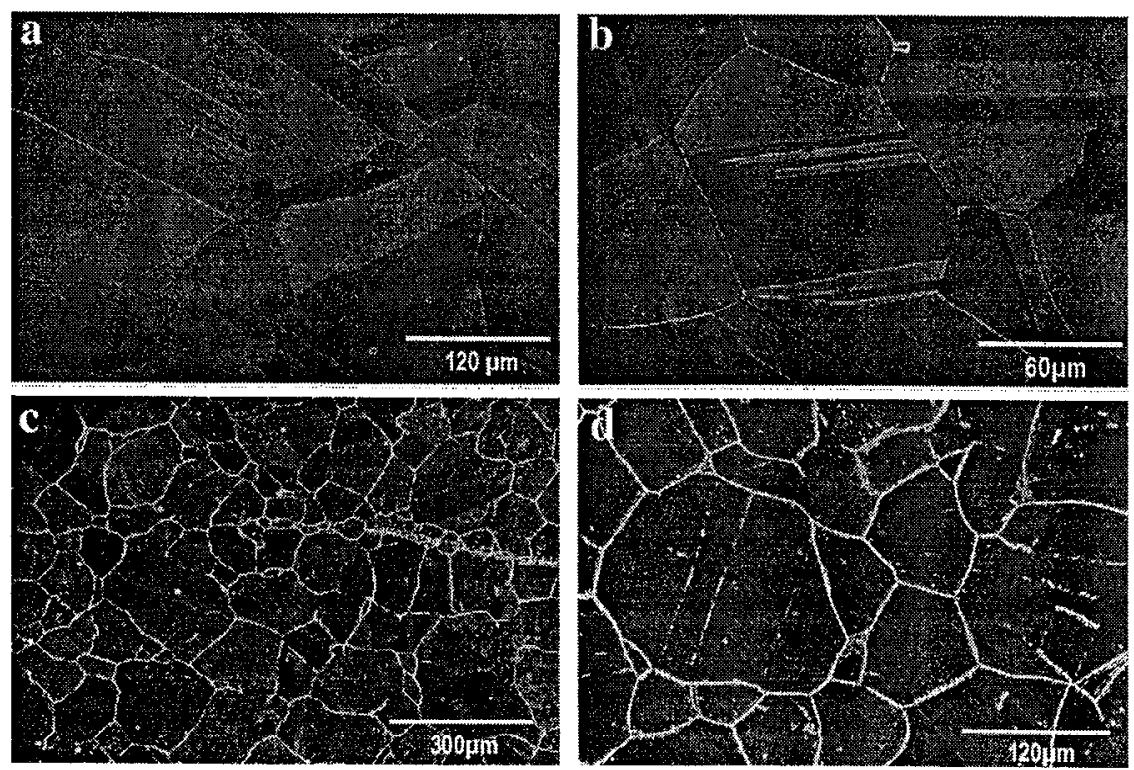

Figure 3-3. SEM micrographs showing the degree of precipitation in C-22 in (a) the mill annealed condition and after aging at $760^{\circ} \mathrm{C}$ for (b) $1 \mathrm{~h}$, (c) $10 \mathrm{~h}$, and (d) $119 \mathrm{~h}$. 


\subsection{Kinetics of Intermetallic/Carbide Precipitation}

Typical SEM micrographs showing the various stages of precipitation in $\mathrm{C}-22$ alloy at $760^{\circ} \mathrm{C}$ are shown in Figure 3-3. Micrographs such as these were used to develop the TTT diagram shown in Figure 3-4 that indicates the time at which grain boundary precipitation begins, the time at which the grain boundaries become covered with precipitation, and the time at which bulk precipitation begins. No distinction has been made in this preliminary study between the various intermetallic and carbide phases that form. It is difficult to distinguish the different phases in SEM. Instead, it is assumed that the $P$ and $\mu$ phases are kinetically similar and that there is only a small amount of carbide and $\sigma$ phase, which is what was seen here and in a previous study (Summers et al. 1998). The curve associated with LRO came from TEM observations. Only a limited number of samples were examined in TEM. Thus, it is likely that ordering occurs at shorter times than indicated in Figure 3-4.

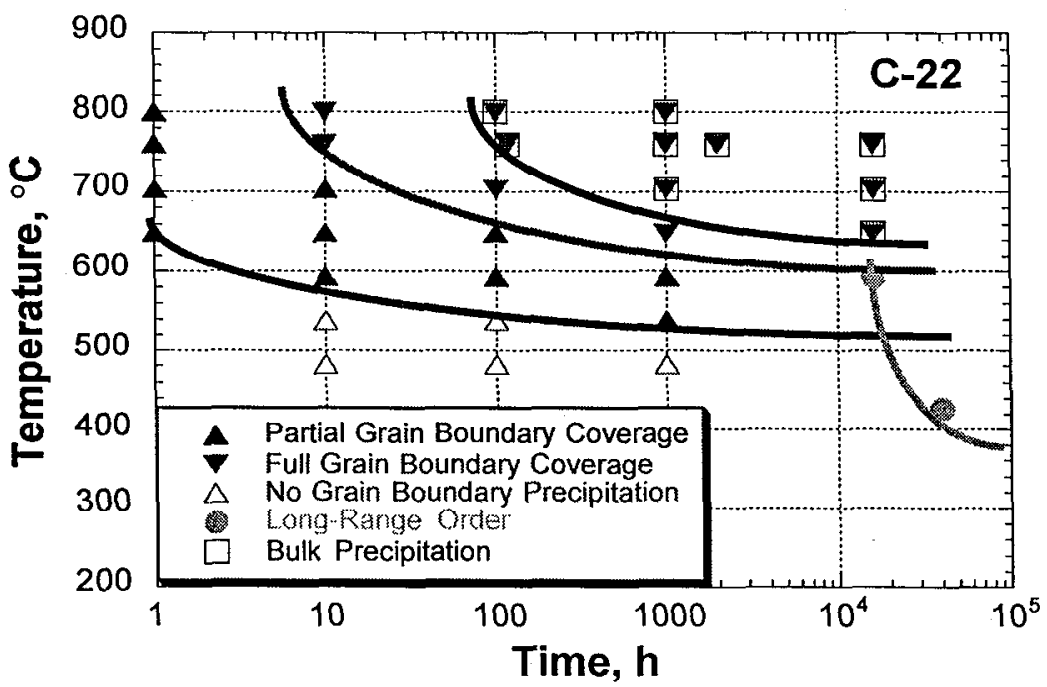

Figure 3-4. TTT diagram for C-22. The grain boundary precipitation was determined through SEM examination. LRO could only be seen in TEM. Since only the samples aged for 16,000 and 40,000 $\mathrm{h}$ were examined in TEM, the true position of the LRO curve could be shifted to shorter times. 


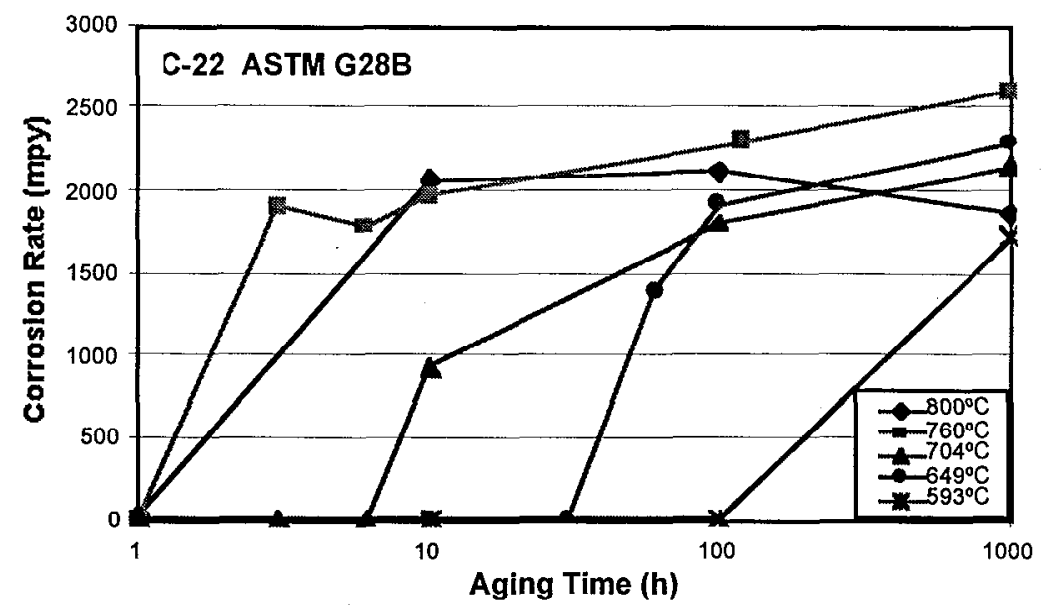

Figure 3-5. The corrosion rate of aged C-22 samples measured using ASTM Specification $\mathrm{G} 28 \mathrm{~B}$ as a function of aging time and temperature.

\subsection{Corrosion Properties of Aged C-22}

The corrosion rates of C-22 alloy as a function of aging temperature and aging time using the ASTM G28B procedure are shown in Figure 3-5. The corrosion rates show a stepwise increase in rate as time increases at a given temperature. This increase occurs some time after the onset of grain boundary precipitation but before the boundaries are completely covered. The corrosion rates of mill-annealed samples was 4.9 mil per year (mpy).

\section{DISCUSSION}

The TTT diagram of Figure 3-4 is similar to that published by Heubner et al. (1989). In this study, the boundary for the onset of precipitation is shifted slightly to lower temperatures and shorter times probably because it is easier to see the beginning of precipitation at grain boundaries in a SEM than in an optical microscope, which is what was used by Heubner et al. (1989). The curve in Figure 3-4 for the beginning of bulk precipitation begins at longer times than in Heubner's diagram. 
Here, precipitation on twin boundaries, which occurs before precipitation within the grain matrix, was not included in bulk precipitation.

TTT diagrams are useful when the temperature the material is to experience in service falls within the range covered by the diagram. It is difficult, however, to extrapolate a TTT diagram from empirical data alone to lower temperatures. For that, the kinetics must be measured directly. Nucleation and growth kinetics can often be represented by an equation of the form

$$
f=1-\exp \left(-k t^{n}\right)
$$

where $\mathrm{f}$ is the volume fraction of the precipitating phase, $\mathrm{t}$ is the time at the aging temperature, and $\mathrm{k}$ and $\mathrm{n}$ are constants (Christian 1975). The value of $k$ depends on the nucleation and growth rates, and thus depends strongly on temperature according to the following law:

$$
\mathrm{k}=\mathrm{C}_{1} \exp \left(-\mathrm{C}_{2} / \mathrm{T}\right)
$$

where $\mathrm{C}_{1}$ and $\mathrm{C}_{2}$ are constants, and $\mathrm{T}$ is the temperature. Experimental measurements of volume fraction as a function of aging time generally fit equation (4.1) better during the early stages of precipitation. However, since changes in the corrosion resistance of C-22 alloy seem to be associated with the early stages of precipitation, equation (4.1) would properly describe the aging of this alloy.

Ideally, the volume fraction of precipitation would be measured as a function of time and temperature and fit to equation (4.1). Instead, as a first estimate of the kinetics of intermetallic precipitation, the time at which the various stages (i.e., some fixed volume fractions) of precipitation are reached was estimated through examination of micrographs such as those in Figure 3-3. Combining equations (4.1) and (4.2) at constant volume fraction yields:

$$
\ln \left(t_{f}\right)=\frac{C_{2}}{n} \cdot \frac{1}{T}+C_{f}
$$

where $t_{f}$ is the time to yield a given volume fraction $f$, and $C_{f}$ is a constant for a given volume fraction.

Plots of $\log$ (time) vs. reciprocal temperature for the various precipitation stages are given in Figure 4-1. The time at which the 
ASTM G28B corrosion rate increases (taken as the time midway between the last time exhibiting the starting corrosion rate and the first timc at which the corrosion rate had increased) is also plotted. Only two points are plotted for the time at which grain boundary precipitation starts. At the higher temperatures, grain boundary precipitation was seen to have already begun after 1 hour, which is the shortest aging time used in this investigation. Since precipitation on grain boundaries actually began at shorter times, these times were not plotted. The time at $649^{\circ} \mathrm{C}$, however, was plotted because precipitation had only just started at a few sites at the grain boundaries in that sample.

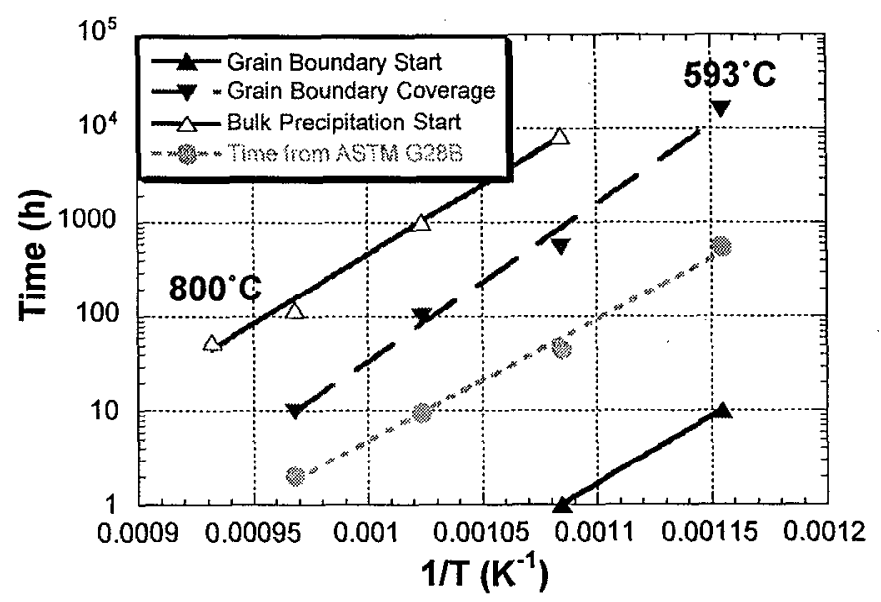

Figure 4-1. The time to reach various stages of precipitation and the time at which the ASTM G28B corrosion rate increases in aged C-22 plotted on a log scale as a function of reciprocal temperature (see equation 4.3 ).

The slopes of the curves in Figure 4-1 (after accounting for the $\log (\mathrm{e})$ factor) are equal to $\mathrm{C}_{2} / \mathrm{n}$ in equation 4.3 . If these slopes are averaged, and $n$ is assumed to be equal to one, which is a reasonable value for $n$ (Christian 1975) and is probably the value assumed by Hodge (1973), then an activation energy of $280 \mathrm{~kJ} / \mathrm{mol}(67 \mathrm{kcal} / \mathrm{mol})$ is obtained (for $\mathrm{C}_{2}=$ activation energy/R). This value is very close to the valuc of 260 $\mathrm{kJ} / \mathrm{mol}(62 \mathrm{kcal} / \mathrm{mol})$ obtained by Hodge (1973) for C-276. This value is also fairly typical for diffusion of relevant elements in nickel (Smithells 1992). For example, the activation energy for diffusion of chromium in 
$\mathrm{Ni}$ is $272.6 \mathrm{~kJ} / \mathrm{mol}$, that of iron is $253-270 \mathrm{~kJ} / \mathrm{mol}$, and that of tungsten in $\mathrm{Ni}$ is $300-308 \mathrm{~kJ} / \mathrm{mol}$.

If it can be assumed that the precipitation mechanism does not change, the lines in Figure 4-1 can be extrapolated to give the times that can be expected for the various stages of precipitation at lower temperatures. No such extrapolation is attempted at this time. This data is preliminary since the times were estimated from examination of micrographs from samples with widely spaced aging times. Extrapolation to lower temperatures is difficult because the precipitation rate is quite sensitive to temperature. In the future, the volume fraction of precipitation will be measured, and the time to give various amounts of precipitation will be taken from a plot of $f$ vs. $t$. This approach should reduce some of the uncertainty in the data plotted in Figure 4-1 and allow extrapolation to lower temperatures. In any case, the preliminary results displayed in Figure 4-1 do not indicatc that precipitation of intermetallics in C-22 alloy base metal will be a problem below about $300^{\circ} \mathrm{C}$.

Any attempt at extrapolation of data such as that in Figure 4-1 to lower temperatures is based on isothermal aging experiments. The temperature in the repository is not expected to remain at the maximum allowed temperature for an extended length of time. It may peak near $350^{\circ} \mathrm{C}$, but it will then slowly decrease. On average, the temperature will be less than $350^{\circ} \mathrm{C}$, and the actual container lifetime can be expected to be longer than would be indicated from an extrapolation of the Arrhenius plots. A more complete reaction rate model based on equation 4.1 must be developed to enable integration over time with a variable temperature profile.

\section{CONCLUSIONS}

After aging for $16,000 \mathrm{~h}$ at $593^{\circ} \mathrm{C}, \mathrm{P}$ phase was found at $\mathrm{C}-22$ alloy grain boundaries. At higher temperatures (up to $760^{\circ} \mathrm{C}$ for the same aging time), both $\mu$ and $P$ phase formed on grain boundaries and within the grains. Grain boundary carbides also form at $593^{\circ} \mathrm{C}$ and above, but the amount of carbide is small compared to the $\mu$ and $\mathrm{P}$ phases. A small amount of $\sigma$ phase forms in C-22 alloy after $16,000 \mathrm{~h}$ at 704 and $760^{\circ} \mathrm{C}$. 
LRO was seen after aging for $16,000 \mathrm{~h}$ at $593^{\circ} \mathrm{C}$ and for $40,000 \mathrm{~h}$ at $427^{\circ} \mathrm{C}$, but ordering most likely begins at shorter times.

The times at which various stages of intermetallic precipitation occur in C-22 alloy displayed an exponential (Arrhenius-type) temperature dependence. The activation energy was determined to be $280 \mathrm{~kJ} / \mathrm{mol}$. Although preliminary, extrapolation of the high-temperature data to lower temperatures suggests that C-22 alloy would remain a single-phase solid solution for times in excess of 10,000 years at temperatures less than $300^{\circ} \mathrm{C}$. A more quantitative model that can be integrated over a variable temperature profile and corrosion data in environments that are more relevant to the potential repository site are needed for a more reasonable prediction.

\section{ACKNOWLEDGEMENTS}

The authors appreciate the efforts of E. Sedillo in metallography and SEM characterization and R. Gross in TEM sample preparation. Helpful discussions with M. Kumar, M. Wall and P. Turchi are also appreciated. This work was performed under the auspices of the U.S. Department of Energy by Lawrence Livermore National Laboratory under contract No. W-7405-Eng-48. This work is supported by Yucca Mountain Site Characterization Project, LLNL.

\section{REFERENCES}

ASTM, 1997, Annual Book of ASTM Standards, vol. 2.04, American Society for Testing and Materials (ASTM), PA, 409-413.

Christian, J.W., 1975, The Theory of Transformations in Metals and Alloys, $2^{\text {nd }}$ edition, Pergamon, Oxford.

Cieslak, M.J., Headley, T.J., and Romig, Ir., A.D., 1986, The Welding Metallurgy of HASTELLOY Alloys C-4, C-22, and C-276. Met. Trans. A 17A: 2035-2047.

Heubner, U.L., Altpeter, E., Rockel, M.B., and Wallis, E., 1989, Electrochemical Behavior and Its Relation to Composition and Sensitization of NiCrMo Alloys in ASTM G-28 Solution. Corrosion 45 (3): 249-259.

Hodge, F.G., 1973, Effect of Aging on the Anodic Behavior of Ni-Cr-Mo Alloys. Corrosion 29: 375-383.

Hodge, F.G., and Kirchner, R.W., 1976, An Improved Ni-Cr-Mo Alloy for Corrosion Service. Corrosion 32: 332--336. 
Leonard, R.B., 1969, Thermal Stability of Hastelloy Alloy C-276. Corrosion 25: 222-228.

Matthews, S.J., 1976, Thermal Stability of Solid Solution Strengthened High Performance Alloys. In Superalloys: Metallurgy and Manufacture (B.H. Kear, D.R. Muzyka, J.K. Tien, and S.T. Wlodek, eds.), Claitor's Publishing Div., Baton Rouge, pp. 215-226.

Raghavan, M., Berkowitz, B.J., and Scanlon, J.C., 1982, Electron Microscopic Analysis of Heterogeneous Precipitates in Hastelloy C-276. Met. Trans. A 13A: 979-984.

Rebak, R.B., and Koon, N.E.,1998, Localized Corrosion Resistance of High Nickel Alloys as Candidate Materials for Nuclear Waste Repository, Effect of Alloy and Weldment Aging at $427^{\circ} \mathrm{C}$ for up to $40,000 \mathrm{II}$, presented at the NACE Corrosion 98 Conference, San Diego, CA (Paper 153, NACE International, Houston).

Smithells Metals Reference Book, Seventh Edition. 1992, ed. by E.A. Brandes and G.B. Brook, Oxford, UK: Butterworth-Heinemann.

Summers, T.S.E., Wall, M.A., Kumar, M., Matthews, S.J., and Rebak, R.B., 1998, Phase Stability and Mechanical Properties of C-22 Alloy Aged in the Temperature Range 590 to $760^{\circ} \mathrm{C}$ for 16,000 Hours. Presented at the MRS Annual Meeting, Symposium QQ, Boston.

Tawancy, H.M., Herchenroeder, R.B., and Asphahani, A.I., 1983, High-Performance NiCr-Mo-W Alloys. J. of Metals 35: 37-43.

Tawancy, H.M., 1996, Precipitation Characteristics of $\mu$-Phase in Wrought Nickel-Base Alloys and Its Effect on Their Properties. J. Mat. Sci. 31: 3929-3936; 1980, OrderStrengthening in a Nickel-Base Superalloy (Hastelloy Alloy S). Met. Trans. A 11A: 1764-1765. 